\title{
Establishment and Application of Multi-Factor Pricing Model in China A-Shares Market
}

\author{
Zhipeng Wu ${ }^{1}$, Jiayi Wang ${ }^{2}$, Benchang Wang ${ }^{1}$ \\ ${ }^{1}$ Department of Financial Engineering \& Quantitative Investment, Tebon Fund Management Company Limited, Shanghai, China \\ ${ }^{2}$ Saint John's Preparatory School, Saint Cloud, USA
}

Email address:

wuzp@dbfund.com.cn (Zhipeng Wu),jwang001@sjprep.net (Jiayi Wang), wangbc@dbfund.com.cn (Benchang Wang)

\section{To cite this article:}

Zhipeng Wu, Jiayi Wang, Benchang Wang. Establishment and Application of Multi-Factor Pricing Model in China A-Shares Market. International Journal of Economics, Finance and Management Sciences. Vol. 6, No. 3, 2018, pp. 118-123. doi: 10.11648/j.ijefm.20180603.17

Received: April 26, 2018; Accepted: May 18, 2018; Published: June 20, 2018

\begin{abstract}
Quantified investment refers to quantitative investment model and the way of issuing orders by programming, so as to obtain stable returns. In recent years quantitative investment is increasingly valued by institutional investors and hedge funds in terms of its discipline, systematicness, timeliness and decentralization. From the perspective of the effectiveness of China's securities market and the development experience of foreign securities market, the prospect of quantified investment is worth looking forward to. However, domestic quantitative investment products still have shortcomings such as small overall size, single quantitative strategy, differentiation of strategic performance. Therefore, it is of great significance to study the new quantitative investment mode and to dig out new modeling ideas to enrich the quantitative investment products, improve the market scale and promote the development of quantitative investment. Based on the method indicated by Eugene Fama and Kenneth French and using public information from China A-share market. This paper attempts to establish a multi-factor model which is able to explain the stock price in Chinese stock market. The model is based on four fundamental factors, including liquidity, profitability, growth opportunity and earning revision. In addition, four fundamental factors are further derived to ten factors. The effectiveness of the ten-factor model is tested by using historical data. The results show that this model could beat the market standard effectively and provide relatively stable excess income.
\end{abstract}

Keywords: China A-Share Market, Multi-Factor Model, Pricing Model

\section{Introduction}

Capital Asset pricing model (CAPM) is the foundation of the modern finance theory. This theory is developed from the traditional pricing model starting as discount cash flow model (DCF) by John Burr Williams (1938) [1]. The model indicates that the price should be the present value of the future cash flow generated from the asset. Harry Markowitz (1952) [2] proposes the Mean-Variance model. In this model, mean of the stock return is used to measure the expected return and the variance of the stock return shows the risk of the stock. The Mean-Variance model is the symbol of the beginning of the modern investment theory. Twelve years later, William Sharpe publishes the CAPM [3] based on formal Portfolio Theories, also known as the single factor model. It suggests that the expected return of the investment portfolio is related to the systematic risk. As the research goes on, Eugene Fama and Kenneth French presents the
Fama-French three-factor model in their thesis "Common risk factors in the returns on stocks and bonds" in 1983. This paper discusses the impact of three stock market factors on the stock price and return, which are market risk (Rm-Rf), the outperformance of small versus big companies (SMB), and the outperformance of companies with high book/market ratio versus that with small book/market ratio (HML). In addition, Eugene Fama and Kenneth French (1993) [4] indicate that the bond market factors, term structure of interest rate and payment risk, can influence the stock price as well. In conclusion, the stock and bond market risk factors can explain the price of the stock in some extent. Compared with CAPM, Fama-French three-factor model can explain the stock price more effectively.

Based on the method indicated by Eugene Fama and Kenneth French (1993), this paper attempts to establish a multi-factor model which is able to explain the stock price in China's stock market. The model is based on four factors, 
including liquidity, profitability, growth opportunity and earning revision. In addition, four factors are further derived to ten factors. Therefore, this paper extends the three-factor model to ten-factor model. The effectiveness of the ten-factor model is tested by using historical data. The experiential window of this paper is from 2010 Aug to $2017 \mathrm{Dec}$.

\section{Model and Methodology}

\subsection{Liquidity}

According to the liquidity premium theory [5], the liquidity of the asset has important influence on asset pricing. Amihud and Mendelson (1986) [6] indicate that the liquidity of the asset is negatively correlated with the return on the asset. Since trading the stock with low liquidity incurs high transaction cost, the required yield on the low liquidity stock is high, compared with the stock with high liquidity. Therefore, there is illiquidity premium in the market.

However, it is hard to measure the liquidity of the stock. In general, the stock with high market value or high trading volume has high liquidity. However, these two indicators can not quantify the influence of liquidity on the asset pricing. Amihud (2002) [7] proposes that the ILLIQ factor is able to quantify the liquidity of stock, which can be calculated by using the Equation (1).

$$
\text { ILLIQ }_{\mathrm{iT}}=\frac{1}{\text { Days }_{\mathrm{iT}}} \sum_{\mathrm{t}=1}^{\text {Days }_{\mathrm{iT}}} \frac{\left|\mathrm{R}_{\mathrm{idt}}\right|}{\text { Volume }_{\mathrm{idt}}}
$$

$\mathrm{R}_{\mathrm{idt}}$ is the return of the stock at time $\mathrm{t}$, Volume idt $_{\text {is }}$ the trading volume at time $t$.

ILLIQ measures how a unit of trading volume changes the price of the stock. Therefore, the stock with higher ILLIQ is more illiquid than the stock with lower ILLIQ. The suitability of ILLIQ factor in China A-share market is tested by using historical data. The experiential window is from 2010 Aug to 2017 Dec. The independent factor is the ILLIQ of each stock in A-share market in the experiential window. The dependent factor is the price of each stock on time $t+1$. For each stock, 90 set of data is obtained, and then the cross-regression is conducted. The average beta of cross-regression is 63.32, and the average $\mathrm{P}$-value is $1.87 \%$. In conclusion, ILLIQ factor has significant positive influence on the stock price. Besides, we used the factor ILLIQ as a single-factor and tested its stock selection ability. In order to get a general reflection of China's A shares market stock price, this study uses CSI300 index as indicator of portfolio behavior. As Figure 1 shows, ILLIQ can beat the market effectively.

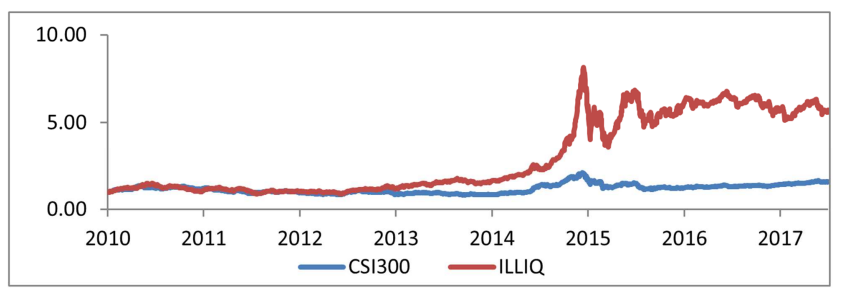

Figure 1. Back Testing of ILLIQ
Therefore, this paper use ILLIQ as one of the factors in the stock pricing model.

\subsection{Quality of Earnings}

Fundamental analysis is always the most direct way to find companies with high quality no matter in bull market or bear market. The quality of earnings of a listed company decides the continuity of their future profitability. Higher quality earnings have higher chances of remaining than those of lower quality earnings. As a direct indicator of a company's Return of Investment (ROI), Return on assets (ROA) and Return on Equity (ROE) are indicators for quality of the company's earnings as well. Meanwhile, this study adds the Gross Margin Percentage in the model so as to take the appreciation of a product generated by the company's transformation into account. Calculation of the three indicators are using the Equations (2), (3), (4):

$$
\begin{gathered}
\mathrm{ROA}=\frac{\text { Net Income }}{\text { Average Total Assets }} \\
\mathrm{ROE}=\frac{\text { Net Income }}{\text { Book Value Of Equity }} \\
\text { Gross margin Percentage }=\frac{\text { Revenue-COGS }}{\text { Revenue }} * 100
\end{gathered}
$$

As Figure 2 shows, those three factors can also beat the market effectively.

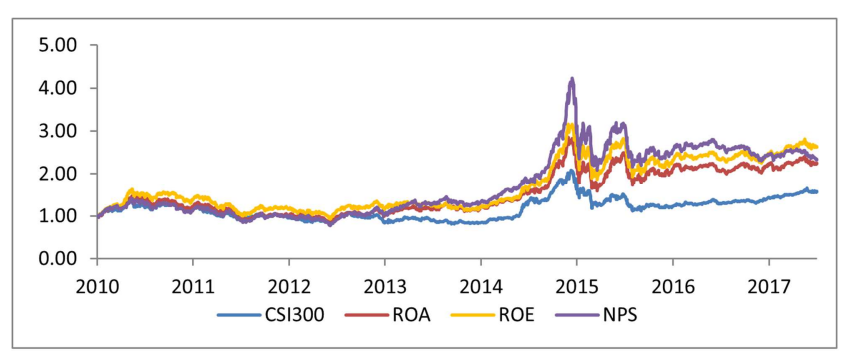

Figure 2. Back Testing of Quality of earnings Factors.

\subsection{Growth Potential}

Since Robert Gibrat proposed Gibrat's Law (1931) [8], more scholars started to research on elements contributing to a company's Growth Potential. There are mainly two types of theories about Growth Potential, deterministic and stochastic. Deterministic theory states that company's characteristics and the industry the company in decide the growth rate altogether. Stochastic theory believes that growth rates are independent from now or future records of the company therefore they are distributed randomly. This paper agrees with deterministic theory. Since a company's growth is a continuous process starting from being established to growing into certain state, the company's current state is related to its history records. With accumulated earnings, the company's capital accumulates and the company's size grows. Meanwhile, the structure of the company will be more organizational and mature. The strengthen in the company's different parts will reflect on its earning ability eventually. Therefore, it is very important 
to conduct Fundamental analysis.

Cliff Asness (1997) [9] is a scholar supporting Fundamental Analysis. He believes that a company's fundaments are main factors that affect its stock price, even though other factors may have small effect on the stock price as well. In terms of stock price, good behavior of fundaments brings more attention from more investors therefore contribute to rise of stock price. On the other hand, investor will hesitate over bad fundaments behaviors therefore contribute to fall of stock price. The Theory was supported by other scholars. Zhang Chen (1998) [10] proves both part of Cliff Asness Theory separately. His research supported the statement that good fundamental behaviors brings more interest and contributed to the rise of stock price while bad fundaments behavior brings skeptical for companies, therefore have negative influence over stock price. Joseph D. Piotroski (2000) [11] supported the theory and made a more detailed division based on it. He chose multiple factors from the company's finance statements as factors of the company's stock price. Then he scored companies based on those factors by setting thresholds, ranked those companies according to the scores and used only top $20 \%$ as his investment combination. He found that he could remain a smaller level of risk while withholding a relative high return, therefore he believes that Fundamental analysis based on companies' financial reports can increase return of investments. This study is going to use revenue growth rate (RevQ), profit growth rate (ProQ) and Net Profit Growth Rate (NetProQ) those three fundamental indicators to evaluate the growth potential of a company.

As Figure 3 shows, those three factors can also beat the market effectively.

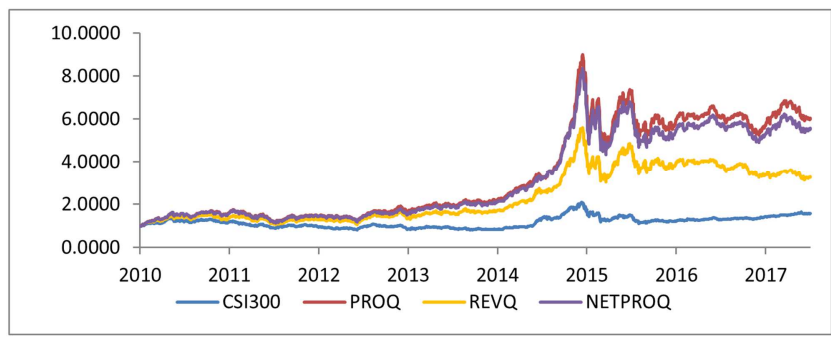

Figure 3. Back Testing of Growth Potential Factors.

\subsection{Earning Revision}

Profit forecast are fundamental statistics to describe corporate income level given by Financial Analysts. Financial analysts' main job function is to collect, analyze and spread information. Financial analyst plays a crucial role in improving communication between listed companies and investors by visiting the facility in real life, researching the business's financial statements and making judgement over industrial trend. Meanwhile analysts summarize their research result into formal Profit Forecast of a company and publish them to the capital market occasionally. It is fair to say that Profit Forecast contains professional study of listed companies and general judgements for quality of returns.
From the view of quantitative investments, Profit Forecast is the only fundamental data source concerning the future of a company among many data types. Historical factor is usually the main factor related to choosing stock according to traditional quantitative stock models. However, those historical factors have already been reflected on the current stock price based on Efficient Markets Hypothesis [12]. Using Profit forecast to build pricing model could avoid the effect from such phenomenon. Erica Slgter and Dick Van Dijk (2003) [13] did research on stock choosing strategy based on Jaapvan der Hart's Theory and discovered that value strategy, momentum strategy and profit forecast strategy produced the highest excess income. Therefore profit forecast produces a large portion of excess income during investment practices. By calculating analyst prediction change over the company's profit forecast, Profit forecast strategy can bring latest view of the market prediction over the company's future into the model, therefore being able to predict excess income brought by the stock.

To sum all, profit forecast strategy is analyst making adjustment over company profit forecast based on all information at hands. Because of anchoring effect, increase or cut of profit forecast will not happen in one time but rather in many steps. Certain behavior provides others with chances to arbitrage.

On the other hand, analysts who only have limited effort tend to cover companies with more chances. When analysts are not optimistic about the future of a company, they will not publish reports in order to maintain a good relationship with list companies. Therefore there are definitely selection base for analysts. Companies with good fundaments, more future chances and higher future profit prediction will be chosen to cover by more analysts [14].

The study uses profit forecast data from Wind [15] to build such factors:

1). Sales change in one month (SalesChange1M)

2). Net profit change in one month (NetProfitChange1M)

3). Coverage change in one month (CoverageChange)

As Figure 4 shows, those three factors can also beat the market effectively.

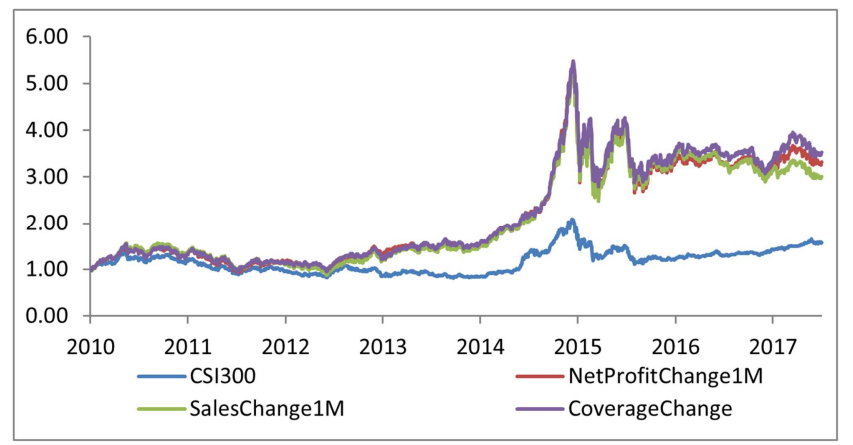

Figure 4. Back Testing of Earning Revision.

\subsection{Pricing Model}

In conclusion, mobility, profitability, growth and profit forecast which including ten factors, can reflect the real value 
of a company. Historical data from Stock Market will be used to verify this. The study uses $\mathrm{T}$ day Closing Price as the dependent variable and the above ten factors as independent variables to build the following regression mode which is Equation (5):

$$
P_{i, T}=\sum_{j=1}^{10} \beta_{i, j} X_{i, j, T-1}+\varepsilon_{i, T}
$$

In the formula (5), X means the factor, subscript means the $\mathrm{T}-1$ value of stock $\mathrm{i}$ under factor $\mathrm{j}$. All factors are listed in Table 1:

Table 1. List of Factors.

\begin{tabular}{ll}
\hline Variable & Factor Name \\
\hline X1 & ILLIQ \\
X2 & ROA \\
X3 & ROE \\
X4 & Gross Margin \\
X5 & RevQ \\
X6 & ProQ \\
X7 & Net ProQ \\
X8 & Sales Change 1M \\
X9 & Net Profit Change 1M \\
X10 & Coverage Change \\
\hline
\end{tabular}

This study do not really think stock price can reflect real value of a company since there is stock discount or premium to some extent. In the regression, residual term $\varepsilon_{\mathrm{i}, \mathrm{T}}$ means the real price of stock $\mathrm{i}$ on $\mathrm{T}$ minus real price. According to Benjamin Graham [16], only when a stock's price is far more than its market price (margin of safety), it is worthy to invest in it. In this paper, based on the regression result, margin of safety can be defined as

$$
\text { Margin of Safety }=\frac{\mathrm{P}_{\mathrm{i}, \mathrm{T}}}{\mathrm{P}_{\mathrm{i}, \mathrm{T}}-\varepsilon_{\mathrm{i}, \mathrm{T}}}
$$

$\mathrm{P}_{\mathrm{i}, \mathrm{T}}-\varepsilon_{\mathrm{i}, \mathrm{T}}$ represents the real value of a company. In a word, the lower margin of safety is, the more discount the company is; vice versa, the more promising the company is.

\section{Empirical Study}

This study does the regression on a monthly base. At the end of the month, we calculate the factors of all stocks. But before using them, normalization - data indexation has to be done to all data and analysis after. By doing normalization can avoids abnormal value, making data being dimensionless and adjust factor distribution characteristics. Abnormal value can distort the factors' statistical results and also obstruct factors' presentation in the model. By making data dimensionless, comparability problem is resolved. Numbers or indexes of different units or orders are able to compare with each other or weighting. In other words, factor normalization is the process of seeking common points and reserve differences while remodeling them. All factors are changed to similar order and distribution characteristics, however, at the same time keep the special new stock information factor. There are tons of methods to do normalization, such as 'Min-max Normalization', 'Z-Scores Normalization' and 'Decimal Scaling'. This study uses Z-Scores Normalization [17]. The details are: First, divide the stocks based on the 29 I-grade industries from CITIC; Second, in each cross-section from all industries, using the factor value of each stock minus average cross-section value and then divided by cross-section standard deviation. After normalization, average cross-section value of factors is 0 , cross-section standard deviation is 1 .

Using data from last trading day of last month This study calculate all ten factors listed above and normalized them based on industry and used value of normalized factors as independent variables. Using closing price of first trading day as dependent variables and taking it into regression equation and calculating residual error, Based on the marginal safety equation above, This study calculates the safety margin of every stock correspond to, Here set the safety margin threshold value to 0.67 which means only choose stock with safety margin value smaller 0.67 . Finally, a weighted market share method is used to calculate the weight distribution of the selected stocks, thus constructing the investment portfolio. This study use the opening price of the second trading day as the sales price of prior-period stock and purchase price of period stock. In order to get a general reflection of Chinese A shares market stock price, This study use CSI300 index as indicator of portfolio behavior.

The net worth of portfolio shown as Figure 5:

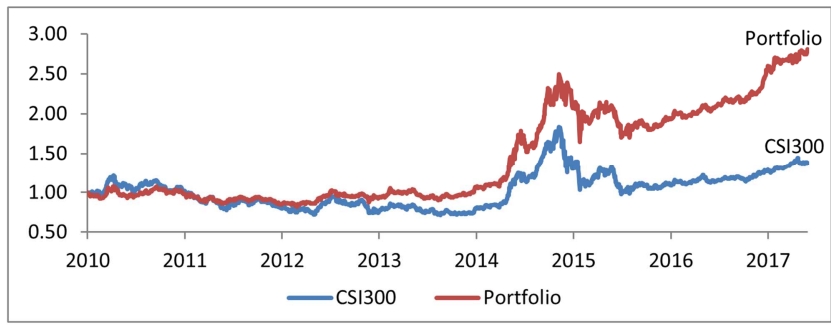

Figure 5. Portfolio Performance.

The active return shows as Figure 6

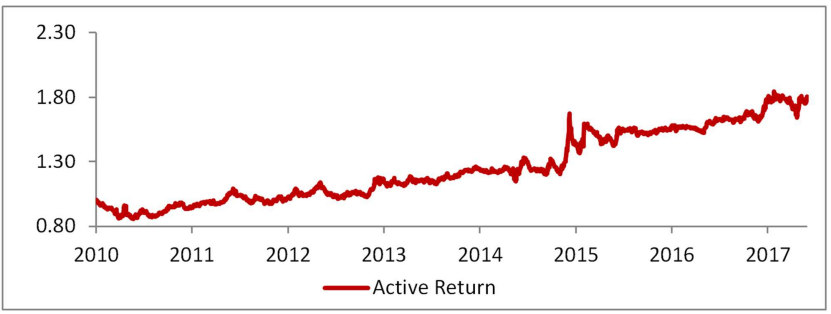

Figure 6. Active Return.

The holding examples shows in the Table 2: 
Table 2. Holdings.

\begin{tabular}{|c|c|c|c|}
\hline StockName & Weight & StockName & Weight \\
\hline QUMEI HOME & $0.06 \%$ & NISCO & $0.75 \%$ \\
\hline 2345 NETWORK HOLDING & $0.69 \%$ & KIBING & $0.54 \%$ \\
\hline AYIS & $0.44 \%$ & SHCI & $3.01 \%$ \\
\hline SHIMGE PUMP & $0.10 \%$ & LIUSTEELCO & $0.73 \%$ \\
\hline LONCIN & $0.50 \%$ & LING STEEL & $0.36 \%$ \\
\hline CHENGDELOLO & $0.33 \%$ & SOUYUTE & $0.42 \%$ \\
\hline CCYS & $0.17 \%$ & ZDDC & $0.63 \%$ \\
\hline XINHU ZHONGBAO & $1.58 \%$ & YANGGU HUATAI & $0.14 \%$ \\
\hline AOTO ELECTRONICS & $0.09 \%$ & NanJi E-Commerce & $0.41 \%$ \\
\hline LEO & $0.34 \%$ & HEILAN HOME & $1.43 \%$ \\
\hline DMG & $0.78 \%$ & QCMC & $0.12 \%$ \\
\hline SEMIR & $0.49 \%$ & YECHIU RECYCLING & $0.30 \%$ \\
\hline MIHF & $0.29 \%$ & JSGT & $0.23 \%$ \\
\hline CHUY AGRO-PASTORAL & $0.31 \%$ & CBM & $0.12 \%$ \\
\hline CNNCTD & $0.23 \%$ & YIWU CCC & $1.19 \%$ \\
\hline SITI & $0.46 \%$ & HDXY & $0.53 \%$ \\
\hline Sino Great Wall & $0.19 \%$ & DEZHAN HEALTHCARE & $0.33 \%$ \\
\hline HY PROPERTY & $0.32 \%$ & AOTECAR & $0.26 \%$ \\
\hline SPC & $1.65 \%$ & JHEC & $0.44 \%$ \\
\hline NANSHAN ALUMINIUM & $0.93 \%$ & CRE & $0.18 \%$ \\
\hline GPED & $0.13 \%$ & QIANHONG BIO-PHARMA & $0.17 \%$ \\
\hline GRGBANKING & $0.48 \%$ & SF DIAMOND & $0.07 \%$ \\
\hline XINTIAN TECHNOLOGY & $0.11 \%$ & UDC & $0.37 \%$ \\
\hline AXXT & $1.22 \%$ & LXDQ & $0.16 \%$ \\
\hline SHANYING PAPER & $0.73 \%$ & TSPGC & $0.67 \%$ \\
\hline AGRICULTURAL BANK OF CHINA & $39.13 \%$ & CHASE SUN PHARM. & $0.37 \%$ \\
\hline DEHUA TB & $0.28 \%$ & FOCUS MEDIA & $2.67 \%$ \\
\hline SDHS & $1.06 \%$ & HXPP & $0.16 \%$ \\
\hline BEFAR & $0.33 \%$ & BANK OF CHINA & $29.40 \%$ \\
\hline GUANGZHOU RESTAURANT & $0.04 \%$ & DTCI & $0.37 \%$ \\
\hline
\end{tabular}

Based on George O. Aragon; Wayne E. Ferson (2006) [18] and Richard C. Grinold and Ronald N. Kahn [19], This study uses these KPIs to measure the behavior the portfolio combination in Table 3

Table 3. Performance Evaluation Indicators.

\begin{tabular}{ll}
\hline Portfolio Return & $181.20 \%$ \\
CSI300 Return & $37.90 \%$ \\
Active Return & $143.30 \%$ \\
Annualized Portfolio Return & $14.97 \%$ \\
Annualized Active Return & $12.74 \%$ \\
Standard Deviation & $20.28 \%$ \\
Sharpe Ratio & 0.74 \\
Information Ratio & 0.92 \\
\hline
\end{tabular}

The KPIs clearly shows that the investment portfolio model beat the market standards easily. The Portfolio return keeps growing as time goes and could still reach $181.2 \%$ of total return after the stock crisis in 2015 .

Number of stocks inside a portfolio always has effect on the portfolio risk level. Based on research from Evans and Archer (1968) [20], fall of portfolio risk level has direct connection with increasing the number of stocks inside the portfolio while choosing asset completely randomly. Soon after, Statman (1987) [21] did similar research to further study diversity's effect on the portfolio. He indicates set holding at least 30 stocks will reach the purpose of spreading the risk. To find the effect of number of stocks on the portfolio, This research added one step in the testing process. Ranking the stocks descending based their safety margin and make an inner join with stocks had safety margin higher than the threshold value, This research took first Nth stocks and build our portfolio. The N's numbers are 20, 30 and 40.

The net worth of portfolios are shows in Figure 7:

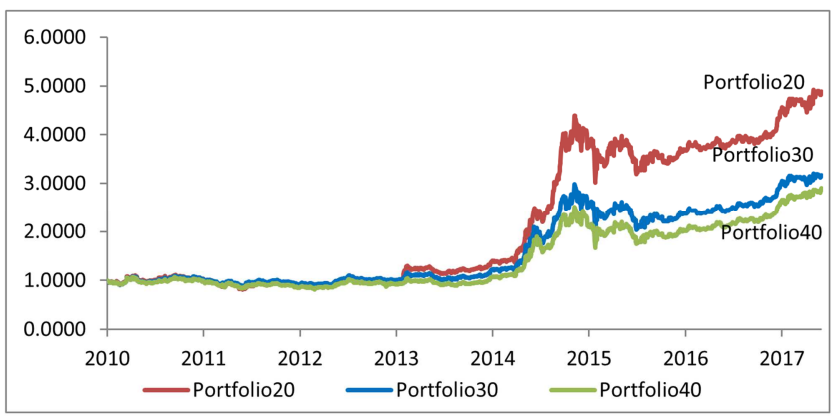

Figure 7. Portfolios Performance.

Portfolio risk level and sharp ratio are shown at Table 4:

Table 4. Standard Deviation and Sharpe Ratio.

\begin{tabular}{lll}
\hline $\mathbf{N}$ & Standard Deviation & Sharpe Ratio \\
\hline 20 & $22.51 \%$ & 1.05 \\
30 & $21.46 \%$ & 0.79 \\
40 & $20.64 \%$ & 0.75 \\
\hline
\end{tabular}

With number of stocks $\mathrm{N}$ increases, the portfolio risk level reduces. When you are holding 20 stocks, you can have 1.05 units of excess income while bearing 1 unit of risk. At the same time, if you are holding 40 stocks, you can have only 
0.75 units of excess income when bearing 1 unit of risk. Therefore, increasing the stock number will decrease the portfolio risk but will decrease the portfolio return as well. This research shows that the best strategy is to hold 20 stocks fulfilling the requirements of safety margin. The KPIs are shown in Table 5:

Table 5. Portfolio 20 Performance Evaluation Indicators.

\begin{tabular}{ll}
\hline Portfolio Return & $388.30 \%$ \\
CSI300 Return & $37.90 \%$ \\
Active Return & $350.40 \%$ \\
Annualized Portfolio Return & $23.85 \%$ \\
Annualized Active Return & $22.85 \%$ \\
Standard Deviation & $22.51 \%$ \\
Sharpe Ratio & 1.05 \\
Information Ratio & 1.45 \\
\hline
\end{tabular}

This study compared the return rate of the model with 752 listed mutual fund return rate to see if such model can beat professional mutual fund manager. As Table 6 shows the highest return insides 752 mutual fund is $340.37 \%$, but our model produce $388.88 \%$ which is a lot higher than the highest.

Table 6. Top 10 Mutual Fund.

\begin{tabular}{ll}
\hline Mutual Fund Name & Return \\
\hline Xing Quan Ho Run Fund & $340.37 \%$ \\
China Universal Private Enterprise Vitality Fund & $300.57 \%$ \\
GuoTai Small and medium Growth Mix Fund & $261.89 \%$ \\
Xing Quan Ho Run Structured Fund & $256.22 \%$ \\
Xing Quan Growth Opportunity Fund & $250.89 \%$ \\
China Universal Selective Hybrid Fund & $240.84 \%$ \\
BOCOM Advantage Industry Mix Fund & $227.33 \%$ \\
China Universal Focused Growth Fund & $218.39 \%$ \\
HSBC Jin Xin Large-Cap Fund & $214.99 \%$ \\
Lombarda China Value Discovery Mix Fund & $214.17 \%$ \\
\hline
\end{tabular}

\section{Conclusion}

This paper proposes a pricing model suitable to China A-share market based on liquidity, earning ability, potential to grow and earning revision. The model uses ten factors to quantify such characteristics of such four dimensions. It uses safety margin to define stock prices' discount level and build portfolio, meanwhile using historical data to validate the model. The test result indicates that the investment portfolio could beat the market standard effectively and provide relatively stable excess income. Furthermore, This research discover that this quantitative investment model could increase the portfolio return by reducing the number of stocks. The optimized portfolio with the model has 20 stocks. With such choice, the investment portfolio built under the model could beat the market standard extensively and even surpass professional portfolio manager's KPI.

\section{References}

[1] John Burr Williams, "The Theory of Investment Value". Harvard University Press 1938; 1997 reprint, Fraser Publishing.
[2] Harry Markowitz, "Portfolio Selection". The Journal of Finance. 7 (1): 77-91. doi:10.2307/2975974. JSTOR 2975974.

[3] William Sharpe, "Capital asset prices: A theory of market equilibrium under conditions of risk". Journal of Finance. vol. 19 (3): 425-442.

[4] Fama, E. F.; French, K. R. (1993). "Common risk factors in the returns on stocks and bonds". Journal of Financial Economics. 33:3. CiteSeerX 10.1.1.139.5892 . doi:10.1016/0304-405X (93) 90023-5.

[5] Wikipedia. "https://en.wikipedia.org/wiki/Liquidity_premium".

[6] Yakov Amihud; Haim Mendelson (1986). “Asset pricing and the bid-ask spread". Journal of Financial Economics. Volume 17, Issue 2, December 1986, Pages 223-249.

[7] Yakov Amihud. "Illiquidity and stock returns: Cross-section and time-series effects". Journal of Financial Markets, 5, 31-56. http://dx.doi.org/10.1016/S1386-4181 (01) 00024-6.

[8] Wikipedia. "https://en.wikipedia.org/wiki/Gibrat\%27s_law".

[9] Clifford S. Asness. "The Interaction of Value and Momentum Strategies". Financial Analysts Journal 53 (2):29-36 • March 1997.

[10] Chen, N., and Zhang, F. (1998). "Risk and Return of Value Stocks". Journal of Business, 71, 5015.

[11] Joseph D. Piotroski. "Value Investing: The Use of Historical Financial Statement Information to Separate Winners from Losers". Journal of Accounting Research. 2000, Vol. 38, Issue Supplement, Pages 1-41.

[12] Fama, Eugene (1970). "Efficient Capital Markets: A Review of Theory and Empirical Work". Journal of Finance. 25 (2): 383417.

[13] Jaapvan der Hart; Erica Slagter; Dick van Dijk. "Stock selection strategies in emerging markets". Journal of Empirical Finance. Volume 10, Issues 1-2, February 2003, Pages 105-132.

[14] Charles M. C. Lee, Eric C. So. "Uncovering expected returns: Information in analyst coverage proxies". Journal of Financial Economics. Volume 124, Issue 2, May 2017, Pages 331-348.

[15] Wind. "http://www.wind.com.cn/".

[16] Graham, Benjamin. Dodd, David. Security Analysis: The Classic 1934 Edition. McGraw-Hill. 1996. ISBN 0-07-024496-0.

[17] Wikipedia. "https://en.wikipedia.org/wiki/Standard_score".

[18] George O. Aragon; Wayne E. Ferson.” Portfolio Performance Evaluation". Jan 1st 2006 Foundations and Trends in Finance volume 2 issue 2 pp 83-190 DOI: 10.1561/0500000015.

[19] Richard C. Grinold and Ronald N. Kahn. "Active Portfolio Management, Second Edition”.

[20] Evans, L. J. and Archer, H. S. "Diversification and Reduction of Dispersion: An Empirical Analysis". The Journal of Finance (1968), 23, 761-767.

[21] Meir Statman. "How Many Stocks Make a Diversified Portfolio?" Journal of Financial and Quantitative Analysis 22 (03):353-363 • September 1987. 